\title{
Impaired nuclear factor erythroid 2-related factor 2 expression increases apoptosis of airway epithelial cells in patients with chronic obstructive pulmonary disease due to cigarette smoking
}

Kazuhiro Yamada, Kazuhisa Asai", Fumihiro Nagayasu, Kanako Sato, Naoki ljiri, Naoko Yoshii, Yumiko Imahashi, Tetsuya Watanabe, Yoshihiro Tochino, Hiroshi Kanazawa and Kazuto Hirata

\begin{abstract}
Background: Cigarette smoking-induced oxidative stress is known to be a key mechanism in COPD pathogenesis. Nuclear factor erythroid 2-related factor 2 (Nrf2) is a central transcription factor that regulates the antioxidant defense system. The aim of this study was to compare Nrf2 expression in COPD subjects and control subjects, and to determine the role of $\mathrm{Nrf2}$ in protecting against oxidative stress-induced apoptosis.

Methods: We enrolled 8 COPD subjects and 7 control subjects in this study. We performed bronchial brushing by bronchoscopy and obtained bronchial epithelial cells from the airways. Nrf2 expression in bronchial epithelial cells was evaluated by real-time PCR and Western blotting. We examined the effect of 10 or $15 \%$ cigarette smoke extract (CSE) induced A549 cells apoptosis using a time-lapse cell imaging assay with caspase-3/7 activation detecting reagent and performed Terminal deoxynucleotidyltransferase-mediated dUTP nick end labelling assay for confirming A549 cells apoptosis. We also examined the effects of Nrf2 knockdown and, 0.1, 0.5, and $1.0 \mathrm{mM} \mathrm{N}$-acetyl cysteine on CSE-induced apoptosis. Statistical analyses were performed using t-test, paired t-test or an analysis of variance followed by the Tukey-Kramer method.

Results: Nrf2 mRNA expression in COPD subjects was significantly lower than that in control subjects and Nrf2 mRNA were negatively correlated with pack year. Nrf2 protein in COPD subjects was significantly lower than that in control subjects. CSE-induced A549 cells apoptosis was increased in a time-, concentration-dependent manner, and was significantly increased by Nrf2 knockdown. N-acetyl cysteine significantly ameliorated CSE-induced apoptosis.

Conclusions: Nrf2 expression was lower in COPD patients than in control subjects. Nrf2 might have a protective role against apoptosis caused by CSE-induced oxidative stress. These results suggest an involvement of Nrf2 in COPD and administration of antioxidants to patients with COPD might be a basic therapeutic option.
\end{abstract}

Keywords: Chronic obstructive pulmonary disease (COPD), Nuclear factor erythroid 2-related factor 2 (Nrf2), Oxidative stress, Apoptosis, Epithelial cell, N-acetyl cysteine (NAC), Cigarette smoke extract (CSE), Time-lapse line cell imaging assay

\footnotetext{
* Correspondence: kazuasai@med.osaka-cu.ac.jp

Department of Respiratory Medicine, Graduate School of Medicine, Osaka

City University, 1-4-3, Asahi-machi, Abeno-ku, Osaka 545-8585, Japan
}

\section{() Biomed Central}

(c) 2016 Yamada et al. Open Access This article is distributed under the terms of the Creative Commons Attribution 4.0 International License (http://creativecommons.org/licenses/by/4.0/), which permits unrestricted use, distribution, and reproduction in any medium, provided you give appropriate credit to the original author(s) and the source, provide a link to the Creative Commons license, and indicate if changes were made. The Creative Commons Public Domain Dedication waiver (http://creativecommons.org/publicdomain/zero/1.0/) applies to the data made available in this article, unless otherwise stated. 


\section{Background}

Chronic obstructive pulmonary disease (COPD) is projected to become the third most prevalent cause of mortality in the world by 2020 [1], and it is a major concern in terms of health economics. Although COPD is defined and categorized by limitations in airflow, it is not a single disease. Pathological changes in COPD include changes in the central or distal airways. The former is considered chronic bronchitis, and this disease is accompanied by an influx of inflammatory cells in the mucosa and airway remodeling, such as epithelial metaplasia and mucus hypersecretion due to hyperplasia of subepithelial mucus glands or goblet cells. The latter is considered emphysema, and alveolar wall destruction and disrupted alveolar attachments to small airway walls are seen with this condition. Inhalation of noxious gas is known to cause COPD, and cigarette smoking, specifically, is recognized as the major cause of COPD. Cigarette smoke has a gas component and a small particulate matter component of less than $5 \mu \mathrm{m}$, and with inhaled cigarette smoke, these components will reach the small airways and evoke pathological changes in the alveolar walls. Oxidative stress is now recognized as a major predisposing factor in the pathogenesis of COPD. Cigarette smoke contains reactive oxygen species (ROS) and each puff of tobacco smoke contains approximately $1 \times 10^{17}$ oxidant molecules [2]. ROS can cause oxidative stress and play a major role in cell apoptosis through injury induced by cigarette smoke [3]. Excessive loss of alveolar epithelial cells and endothelial cells by apoptosis has been postulated to lead to the destruction of lung tissue and emphysema.

Nuclear factor erythroid 2-related factor 2 (Nrf2), also known as NFE2L2, is ubiquitously expressed at high concentrations in various human organs including the lungs. Although Nrf2 exists in the cytoplasm with a cluster of proteins that degrade it quickly under normal conditions, following oxidative stress, Nrf2 reaches the nucleus of a cell and binds to the antioxidant response element (ARE) in the upstream promoter region of antioxidant genes and initiates transcription of these genes and expression of these proteins [4]. Nrf2 is a central transcription factor that regulates the antioxidant defense system and acts as a modifier of several lung diseases associated with oxidative stress and inflammation. Murine studies report that the knockdown of Nrf2 made mice highly susceptible to cigarette smokeinduced lung injury $[5,6]$. Moreover, Nrf2 activation in macrophages reduced oxidative stress [7]. These studies suggest that there is a clear link between defects in the lung antioxidant defense system regulated by Nrf2 and oxidative stress-related lung diseases [8]. However, in humans, no previous studies have addressed the relationship of Nrf2 expression to oxidative stress and COPD.
In this study, we determined the level of Nrf2 in the bronchial epithelial cells by RT-PCR and Western blotting, and alveolar epithelial cells by immunohistochemistry in COPD subjects. We also examined the effect of antioxidants and Nrf2 expression on CSE-induced apoptosis in vitro.

\section{Methods}

\section{Human bronchial epithelial cells}

Study subjects were patients scheduled for bronchoscopies for small nodules or a small amount of bloody sputum in an outpatient clinic at Osaka City University. We performed bronchial brushing from the normal side by bronchoscopy and obtained bronchial epithelial cells from the airways of 8 COPD subjects and 7 healthy control (CTL) subjects. COPD is defined by The Global Initiative for Chronic Obstructive Lung Disease (GOLD) guidelines as a post-bronchodilator FEV1 \% (FEV1/FVC) of $<70 \%$ [9]. This study was approved by the ethics committee of Osaka City University Hospital (approval number 1819) and all patients gave written informed consents for their participation.

\section{Real-time PCR}

Total RNA was extracted using $500 \mu \mathrm{L}$ of TRIzol (Life Technologies Japan, Tokyo, Japan) from cells obtained by bronchoscopic bronchial brushing. Reverse transcription of $1 \mu \mathrm{g}$ of total RNA was performed using ReadyTo-Go T-Primed First-Strand Kit (GE Healthcare Japan, Tokyo, JAPAN) . One $\mu \mathrm{L}$ of sample cDNA was added to a PCR mixture containing $1 \mu \mathrm{L}$ of primers targeting Nrf2 and GAPDH by TaqMan Gene Expression Assays (Life Technologies Japan, Tokyo, Japan), $10 \mu \mathrm{L}$ of $2 \times$ Universal PCR Master Mix (Life Technologies Japan, Tokyo, Japan), and $8 \mu \mathrm{L}$ of DEPC Water. Quantitative real-time PCR was performed using an Applied Biosystems 7500 Real-Time PCR System (Life Technologies Japan, Tokyo, Japan). The PCR conditions used in all reactions were: $10 \mathrm{~min}$ at $95{ }^{\circ} \mathrm{C}$, followed by 40 two-step cycles $\left(95{ }^{\circ} \mathrm{C}\right.$ for $15 \mathrm{~s}$ and $60{ }^{\circ} \mathrm{C}$ for $\left.45 \mathrm{~s}\right)$. The relative levels of Nrf2 mRNA were normalized to GAPDH mRNA using the $\Delta \Delta \mathrm{Ct}$ method.

\section{Western blotting and detection}

Cells obtained by bronchoscopic bronchial brushing were suspended in $4 \mathrm{ml}$ of PBS. The PBS were centrifuged at $10,000 \times g$ at $4{ }^{\circ} \mathrm{C}$ for $10 \mathrm{~min}$. Supernatants were discarded and pellet was dissolved with $100 \mu \mathrm{L}$ of cell lysis buffer (Cell Signaling Technology, Danvers, MA, USA) The concentrations of the resulting protein extracts were measured using a BCA Protein Assay Kit (Pierce, Waltham, MA, USA). Ten $\mu$ g of each total protein lysate was subjected to sodium dodecyl sulfate polyacrylamide gel electrophoresis by using Mini-PROTEAN ${ }^{\circ}$ TGX $^{\mathrm{mm}}$ 
Precast Protein Gels (4561023, Bio-Rad, Hercules, California, USA). The membranes were incubated at $4{ }^{\circ} \mathrm{C}$ overnight with primary antibodies against Nrf2 (1:250, ab137550, Abcam, Tokyo, Japan) or $\beta$-actin (1:5000, sc130656, Santa Cruz Biotechnology, Santa Cruz, CA, USA) and were then incubated with secondary antibodies against rabbit IgG produced in goat (sc-2004, Santa Cruz Biotechnology) for $2 \mathrm{~h}$ at room temperature. The densitometry to measure protein level in Nrf2 and $\beta$-actin was performed by using LAS4000 (Fuji Imaging, Tokyo, Japan).

\section{Immunohistochemistry}

Four COPD and four control subjects formalin-fixed, paraffin-embedded lung sections $(4 \mu \mathrm{m}$ thick) were obtained from tissue bank of Osaka City University. For immunohistochemical staining of Nrf2, the usual avidinbiotin complex $(\mathrm{ABC})$ method was employed. Briefly, after deparaffinized, the slides were washed with PBS. The slides were permeabilized with $0.2 \%$ triton (Sigma Aldrich, St.Louis, MO, USA) in PBS and treated with $5 \%$ hydrogen peroxide in PBS for $30 \mathrm{~min}$ at room temperature. The sections were then blocked with $5 \%$ goat serum for $30 \mathrm{~min}$, washed with PBS and incubated overnight with the Nrf2 primary antibody (Santa Cruz Biothechnology, Santa Cruz, CA, USA) at a dilution of 1:100 at $4{ }^{\circ} \mathrm{C}$. The Vectastain $\mathrm{ABC}$ elite kit (Vector Laboratories, Burlingame, CA, USA) was used to detect the resulting immune complexes following the manufacturer's instruction. The peroxidase activity was visualized by using DAB Substrate Kit (SK-4100, Vector Laboratories, Burlingame, CA, USA). The slides were then counterstained with hematoxylin and mounted. Negative controls were performed using nonimmune serum instead of the primary antibody to exclude nonspecific staining. For evaluation of immunoperoxidase staining, two observers blind to clinical information counted immunoperoxidase staining positive alveolar epithelial cells in four non-overlapping fields. Total alveolar septal length of each field was measured by using Image J software (National Institutes of Health, Bethesda, Maryland, USA) and immunoperoxidase positivity of alveolar epithelial cells were adjusted by total alveolar septum length. We calculated the ratio: positive cell number/alveolar septal length.

\section{Preparations of cigarette smoke extract (CSE)}

To mimic cigarette smoking-induced epithelial cell damage, we employed the gas phase of CSE in an in vitro study. CSE was prepared as previously described [10]. Briefly, 40 Marlboro cigarettes (Philip Morris Japan, Tokyo, Japan) were mounted for burning, and the main stream of the smoke was aspirated at a flow rate of $1.05 \mathrm{l} / \mathrm{min}$, which was strictly regulated by the KOFLOC $^{\mathrm{TM}}$ Mass Flow Controller (model 8500 series:
Kojima Instruments Inc., Kyoto, Japan) and passed through a Cambridge glass fiber filter (Heinr, Borgwaldt $\mathrm{GmbH}$, Hamburg, Germany) to remove the tar phase of the smoke and nicotine. The remaining gas phase of the smoke was bubbled into $10 \mathrm{ml}$ of PBS at $25{ }^{\circ} \mathrm{C}$. The medium was filtered with a $0.22 \mu \mathrm{m}$ Millex filter (Merck Millipore, Billerica, MA, USA). This solution was defined as $100 \%$ CSE. The CSE was stored at $-80{ }^{\circ} \mathrm{C}$ before use. CSE was diluted with PBS or cell culture medium for in vitro experiments.

\section{Exhaled breath condensate (EBC)}

To examine the oxidative milieu in smokers' airways, EBC was collected using ECoScreen (Eric Jaeger, Würzburg, Germany). Fifteen minutes of oral EBCs were collected before and after cigarette smoking in healthy smoking volunteers without nose clips. The EBC pH was an easily measurable surrogate marker of oxidative stress in the airway [11] that was measured immediately after collection using a pH analyzer (Horiba, Ltd, Kyoto, Japan).

\section{A549 cell culture}

Cigarette smoke induces alveolar cell apoptosis leading to alveolar wall destruction and emphysema. Therefore, we employed A549 cells derived from adenocarcinomic human alveolar basal epithelial cells for in vitro experiments. A549 cells were obtained from American Type Culture Collection and was grown in DMEM/F12 medium (Lonza Japan, Tokyo, Japan) supplemented with $10 \%$ fetal bovine serum (FBS) on $75 \mathrm{~cm}^{2}$ cell flasks. Cells were grown to $>80 \%$ confluence and passaged to a 96-well plate (Corning 3596, Sigma-Aldrich Japan, Tokyo, Japan) at a density of $1.67 \times 10^{3}$ cells per well in triplicate, such that the next day, cells were approximately 10-20\% confluent. For the time-lapse cell imaging assay, treatment and pretreatment media were prepared as follows. We prepared optimal concentrations of CSE determined by EBC pH and $100 \mu \mathrm{M} \mathrm{H}_{2} \mathrm{O}_{2}$ as a positive control for cell stimulation in bronchial epithelial growth medium (BEGM) (Lonza Japan, Tokyo, Japan). For pretreatment, we prepared the control medium, 0.1, 0.5, and $1.0 \mathrm{mM} \mathrm{N}$-acetyl cysteine (NAC) (Sigma-Aldrich Japan, Tokyo, Japan), 0.1, 1.0, and $5.0 \mu \mathrm{g} / \mathrm{ml}$ anti-TNF- $\alpha$ antibody (mouse monoclonal IgG clone: R\&D Systems, Inc., Minneapolis, MN, USA) in BEGM.

\section{Time-lapse cell imaging assay for apoptosis}

To examine oxidative stress-induced epithelial cell apoptosis and the protective effect of the antioxidant over time, a time-lapse cell imaging assay (IncuCyte ZOOM ${ }^{\circ}$ system with Cell Player $^{\text {Tw }}$ 96-Well Kinetic Caspase-3/7 reagent: Essen BioScience, Ltd., Tokyo, Japan) was performed. 
Caspase-3/7 reagent coupled the activated caspase-3/7 recognition motif (DEVD) to $\mathrm{NucView}^{\mathrm{rm}} 488$, a DNA intercalating dye. When added to tissue culture medium, this inert, non-fluorescent substrate crosses the cell membrane where it is cleaved by activated caspase-3/7, resulting in the release of the DNA dye and green fluorescent staining of nuclear DNA. Kinetic activation of caspase-3/7 can be monitored morphologically using live cell imaging, and quantified using the IncuCyte ZOOM Basic Analyzer or the IncuCyte ${ }^{\text {TM }}$ FLR object counting algorithm. Caspase-3/ 7 reagent was diluted and added to each well for a final concentration of $5 \mu \mathrm{M}$ in each pretreatment media. The 96-well plate was put into a microplate tray in IncuCyte ZOOM. The previously described pretreatment and treatment media were added to each well. The IncuCyte ZOOM acquired phase-contrast images at 3-h intervals over a period of $12 \mathrm{~h}$, and calculated the mean bright green cell count (the Caspase-3/7 positive cell number) from non-overlapping fluorescent images of each well automatically [12]. At the end of the experiment, Vybrant DyeCycle Green (VDCG: Life Technologies Japan, Tokyo, Japan), a cell-permeant DNA-binding fluorophore, was added and incubated for $1 \mathrm{~h}$ to provide an absolute (endpoint) nuclear cell count (the total cell number). We defined the apoptotic index according to the following equation:

Apoptotic index $=$ Caspase-3/7-positive cell number $/$ Total cell number

\section{Nrf2 mRNA knockdown by siRNA}

To examine the protective effect of Nrf2 on oxidative stress-induced epithelial cell apoptosis over time, A549 cells were pre-treated with Silencer select siRNA against Nrf2 (Life Technologies Japan, Tokyo, Japan) and IncuCyte ZOOM system and Cell Player ${ }^{\text {TM }}$ 96-Well Kinetic Caspase-3/7 reagent experiments were repeated. Silencer Negative Control siRNA (Life Technologies Japan, Tokyo, JAPAN) was used as a negative control. A549 cells were transfected with the siRNA complex with Lipofectamine 2000 (Life Technologies Japan, Tokyo, Japan) according to the manufacturer's recommendations. The knockdown efficiency of Nrf2 was quantified by RT-PCR. The A549 cells were seeded in a 96-well plate at a density of $1.67 \times 10^{3}$ cells per well in triplicate. On the next day, cells were transfected with the siRNA complex. Twenty-four hour later, the cells were treated with $10 \%$ CSE and examined the apoptotic index using IncuCyte ZOOM.

Terminal deoxynucleotidyltransferase-mediated dUTP nick end labelling assay (TUNEL) and DAPI staining

To confirm CSE-induced apoptosis, not just Caspase-3/7 activation, TUNEL staining (Roche Diagnostics K.K., Tokyo, Japan) was performed. A549 cells were grown on culture slides and fixed in methanol and acetone. Then, slides were incubated for $1 \mathrm{~h}$ at $37^{\circ} \mathrm{C}$ in the presence of terminal deoxynucleotidyl transferase (TdT). In the negative control, no TdT was added. In addition, after cells were washed with PBS, cells were stained with $2 \mu \mathrm{g} / \mathrm{ml}$ DAPI for $15 \mathrm{~min}$. Slides were observed with a fluorescent microscope at 475-495 $\mathrm{nm}$ for TUNEL and 330-385 nm for DAPI at $\times 400$ magnification.

\section{Statistical analysis}

Statistical analyses were performed using JMP version 10.0.0 software for Windows (SAS Institute Inc., Cary, NC, USA). To compare 2 groups, a t-test or paired t-test was performed. To compare more than 3 groups, an analysis of variance (ANOVA) followed by the TukeyKramer method were performed. In all statistical analyses, $p$-values $<0.05$ were considered significant.

\section{Results}

Nrf2 mRNA and protein level decreased in COPD subjects Subject characteristics were shown in Table 1. There were no significant differences in age or BMI. FEV1.0 and \% FEV1 in COPD subjects were significantly lower than those in the CTL group. Nrf2 mRNA level in COPD subjects was significantly lower than that in the CTL subjects (Fig. 1a). There was significant negative correlation between Nrf2 mRNA expression and packyear (Fig. 1b). Nrf2 protein level in COPD subjects was also significantly lower than that in the CTL subjects (Fig. 1c and d). There were Nrf2 positive epithelial cells in alveolar septum in both COPD and CTL subjects (Fig. 2a). In addition, the ratio of positive cells to alveolar septal length in COPD subjects was significantly decreased compared with CTL subjects (Fig. 2b).

\section{EBC $\mathrm{pH}$ decreased after cigarette smoking}

We measured the EBC $\mathrm{pH}$ in non-COPD smokers before and after cigarette smoking. The first EBC was collected after overnight non-smoking. They were then allowed to smoke 1 cigarette. After 15 min of smoking, the second

Table 1 Subjects, characteristics

\begin{tabular}{llll}
\hline & Control & COPD & $p$-value \\
\hline Subject No. & 7 & 8 & N.S. \\
Sex (male/female) & $(2 / 5)$ & $(6 / 2)$ & \\
Age (year) & $62.7(56.9-68.5)$ & $70.0(64.6-75.5)$ & N.S. \\
BMl $\left(\mathrm{kg} / \mathrm{m}^{2}\right)^{*}$ & $22.4(19.1-25.8)$ & $21.2(18.1-24.3)$ & N.S. \\
Pack-Year* & 0 & $55.9^{* *}(40.1-71.6)$ & $p<0.01$ \\
FEV1.0 (L)* & $2.40(1.89-2.90)$ & $1.40^{* *}(1.00-1.79)$ & $p<0.01$ \\
$\%$ FEV1.0 (\%)* & $88.9(73.4-104.4)$ & $55.0^{* *}(42.8-67.3)$ & $p<0.01$ \\
\hline
\end{tabular}

${ }^{*}$ mean $\left(95 \%\right.$ confidence interval) ${ }^{* *} p<0.05$ compared with control BMI: body mass index

FEV1.0: Forced expiratory volume in one second

$\%$ FEV1.0: percent predicted forced expiratory volume in one second 
a

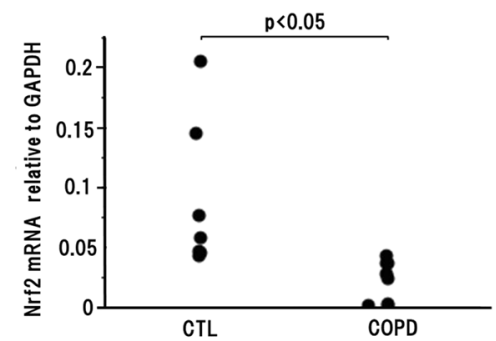

C

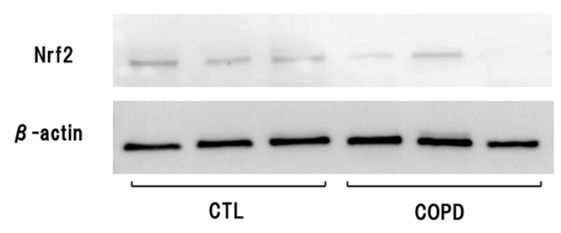

b

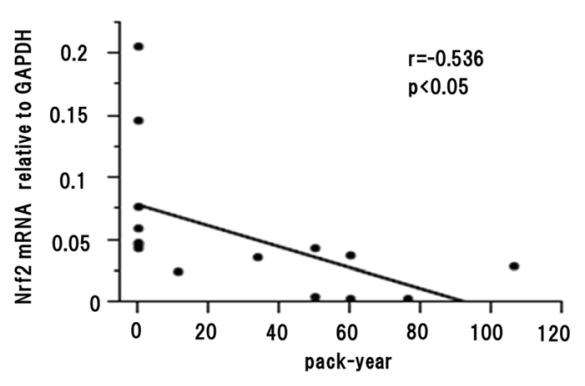

d

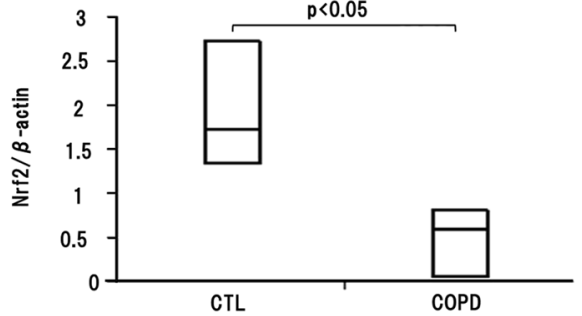

Fig. 1 Nrf2 expression in study subjects. a Nrf2 mRNA expression in COPD subjects were significantly decreased compared with CTL subjects. b Nrf2 mRNA expression was significantly negatively correlated with pack-year. c Western blotting analysis of Nrf2 in bronchial epithelial cells in COPD and CTL subjects. $\mathbf{d}$ The blotting were normalized to $\beta$-actin and measured by densitometry. Nrf2 protein expression in COPD subjects were significantly decreased compared with CTL subjects. CTL: control

EBC was collected. EBC $\mathrm{pH}$ was significantly lower after smoking (Fig. 3). These results indicate that smoking only 1 cigarette can cause oxidative stress in the airway. To mimic the oxidative milieu in smokers' airways in in vitro experiments, we measured the $\mathrm{pH}$ of various concentrations of $\mathrm{H}_{2} \mathrm{O}_{2}$ and CSE diluted in PBS or culture medium. The $\mathrm{pH}$ of $100 \mu \mathrm{M} \mathrm{H}_{2} \mathrm{O}_{2}$ was 7.54. The $\mathrm{pH}$ of 10 and $15 \%$ CSE were 7.75 and 7.56, respectively. We chose 10 and $15 \% \mathrm{CSE}$ as treatments and $100 \mu \mathrm{M} \mathrm{H}_{2} \mathrm{O}_{2}$ as a positive control in in vitro experiments.

\section{CSE-induced epithelial cell apoptosis}

Following $15 \%$ CSE treatment, green fluorescent staining by caspase- $3 / 7$ reagent was higher than that in the control
(Fig. 4a). The apoptotic index was time-dependent and the peak apoptotic index was recorded at $12 \mathrm{~h}$ after treatment (Fig. 4b). The apoptotic index also showed CSE concentration-dependence, and the apoptotic index of cells treated with $15 \%$ CSE was significantly higher that of the control (Fig. 4c). To confirm CSE-induced apoptosis, we performed TUNEL staining in control and $15 \%$ CSEtreated cells. TUNEL fluorescence was higher with $15 \%$ CSE-treated than in the control cells (Fig. 5).

\section{Nrf2 knockdown increased CSE-induced epithelial cell apoptosis}

Nrf2 is a central transcription factor for the antioxidant defense system. Oxidative stress causes apoptosis; therefore,
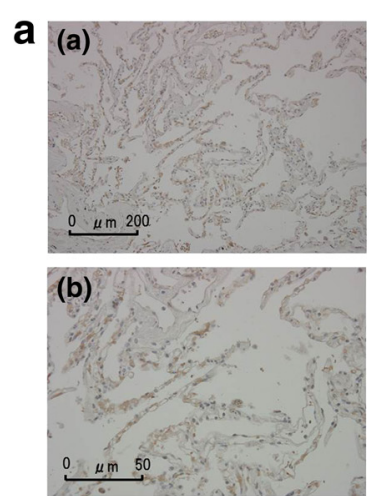
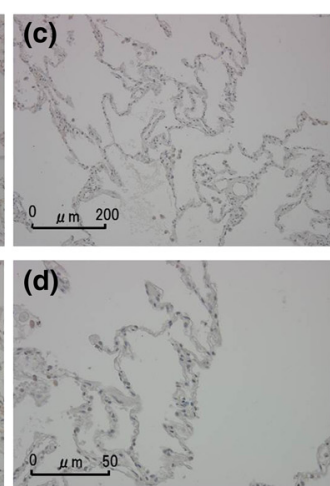

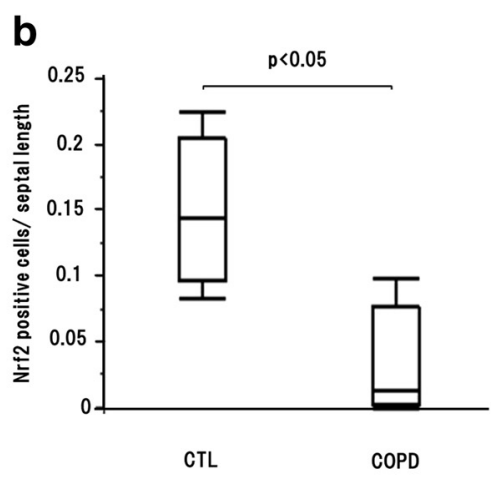

CTL

COPD

Fig. 2 Nrf2 immunohistochemistry. a Immunohistochemical assessment of Nrf2. (a) CTL, x100 magnification, (b) CTL, x400 magnification, (c) COPD, x100 magnification and (d) COPD, x400 magnification. b Nrf2 expression in COPD subjects were significantly decreased compared with CTL in immunohisotochemical assessment. CTL: control 


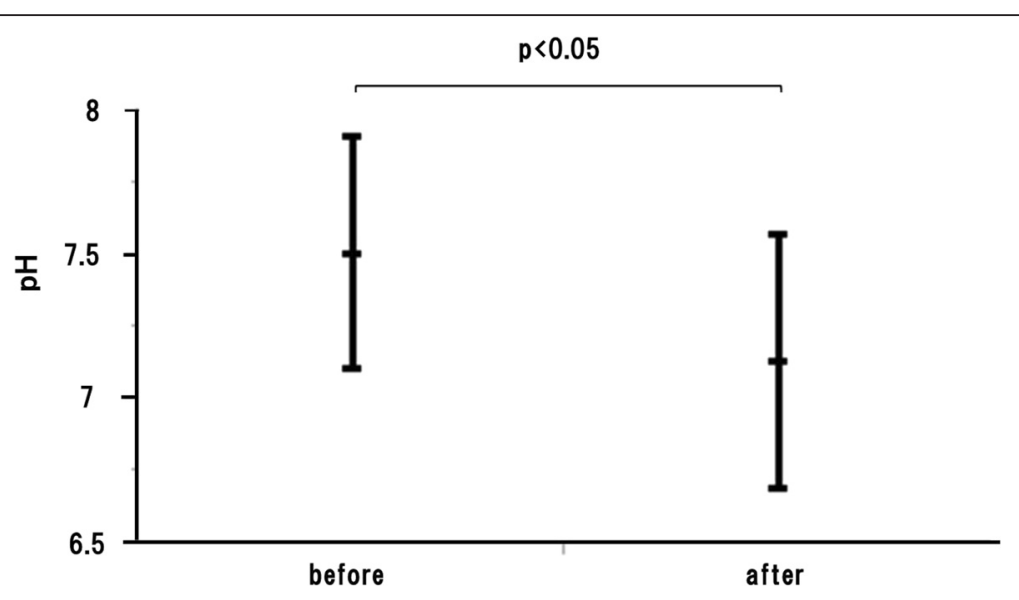

Fig. 3 The $\mathrm{pH}$ of exhaled breath condensate before and after smoking. The pH of exhaled breath condensate (EBC) before and after smoking in non-COPD smoking subjects. The $\mathrm{pH}$ of EBC was significantly decreased after smoking. Data were expressed as Mean \pm SEM

we examined the effect of Nrf2 knockdown on apoptosis of A549 cells. A549 cells transfected with Nrf2 siRNA complex showed significantly decreased Nrf2 mRNA level in control conditions. Further, $15 \%$ CSE treated A549 cells transfected with Nrf2 siRNA complex also showed significantly decreased Nrf2 mRNA level (Fig. 6a), mimicking cigarette smoke-associated COPD airways. $10 \%$ CSE treatment condition and $10 \%$ CSE treatment with Nrf2 mRNA knockdown increased apoptotic index over time (Fig. 6b). Althugh apoptotic index in $10 \%$ CSE treatment was greater than that in control conditions, the difference between the indices did not reach statistical significance. However, the apoptotic index in $10 \%$ CSE with Nrf2 mRNA knockdown was significantly greater than that in control conditions (Fig. 6c). These results suggested that decreased Nrf2 mRNA expression increased CSE-induced apoptosis of A549 cells.

\section{NAC attenuated CSE-induced epithelial cell apoptosis}

We investigated whether NAC protected against CSEinduced epithelial cell apoptosis. Green fluorescent staining by caspase-3/7 reagent in $1.0 \mu \mathrm{M}$ NACpretreated $15 \%$ CSE cells was lower than that in $15 \%$ CSE-treated cells (Fig. 7a). Although pretreatment with
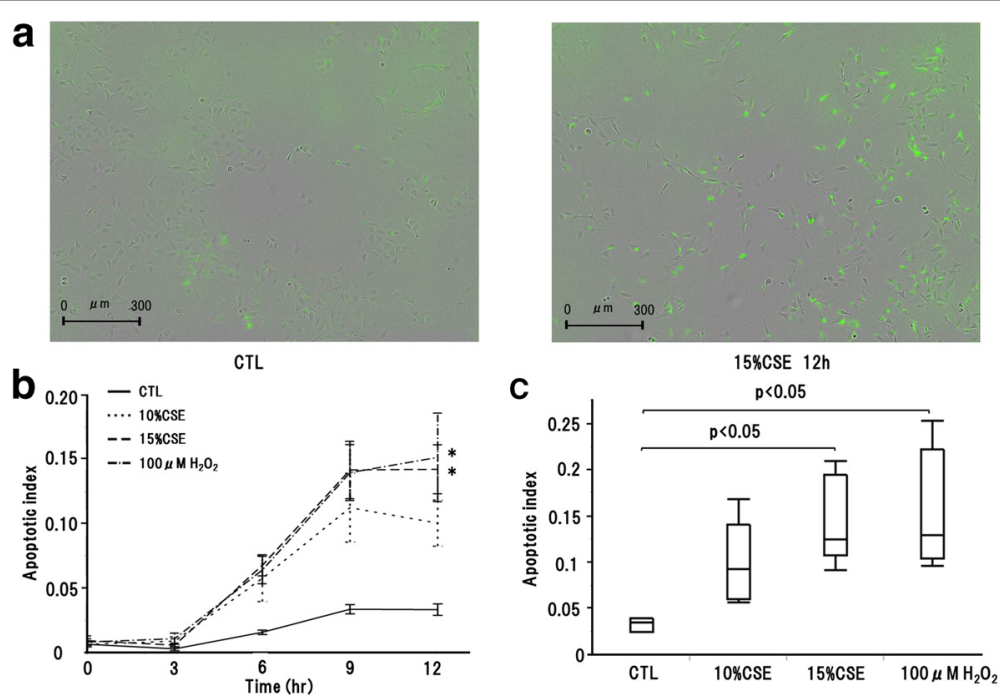

Fig. 4 CSE induced apoptosis. a Green fluorescent staining by caspase-3/7 reagent revealed apoptosis cells. The number of green fluorescent staining was increased in $15 \%$ CSE treatment. b Apoptotic index was increased over time in $10 \%$ CSE, $15 \%$ CSE or $100 \mu \mathrm{M} \mathrm{H} \mathrm{H}_{2} \mathrm{O}_{2}$ treatment compared with CTL. * $p<0.05$ compared with CTL. c Apoptotic index increased depending on CSE concentration. Apoptotic indices in $15 \%$ CSE, $100 \mu \mathrm{M} \mathrm{H}_{2} \mathrm{O}_{2}$ treatment were significantly increased compared with CTL. CTL: control 


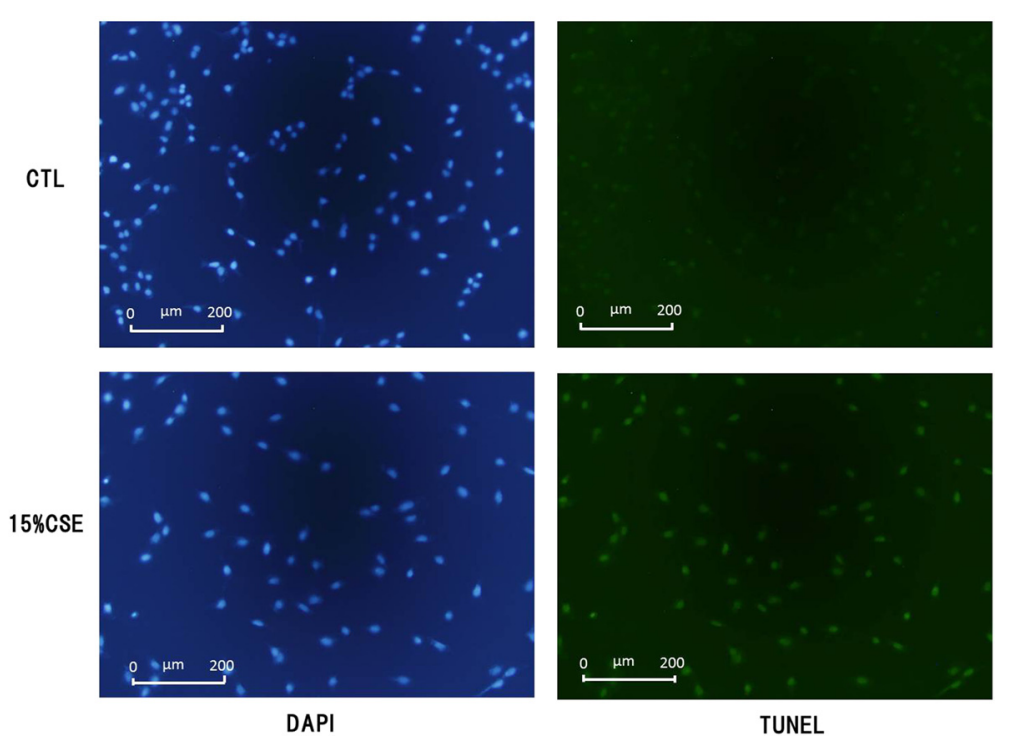

Fig. 5 TUNEL stain in $15 \%$ CSE treatment. DAPI (Left) and TUNEL (right) stain were performed on A549 cells after 24 h of $15 \%$ CSE treatment or control. Nuclei were detected with DAPI fluorescence (blue) Apoptosis were detected with TUNEL fluorescence (green). Increased TUNEL fluorescence was observed in $15 \%$ CSE treatment compared with control

$0.1 \mu \mathrm{M}$ NAC did not reduce the $15 \%$ CSE-induced apoptotic index, pretreatment with 0.5 or $1.0 \mu \mathrm{M} \mathrm{NAC} \mathrm{signifi-}$ cantly reduced the $15 \%$ CSE-induced apoptotic index (Fig. 7b). In contrast, pretreatment with $0.1,1.0$, or $5.0 \mu \mathrm{g} /$ $\mathrm{ml}$ anti-TNF- $\alpha$ antibody did not reduce the apoptotic index of 10 or $15 \%$ CSE-treated cells or of $100 \mu \mathrm{M} \mathrm{H}_{2} \mathrm{O}_{2}$ treated cells (data not shown). These findings suggest that CSE-induced apoptosis is caused by oxidative stress that is not mediated by the TNF- $\alpha$ receptor pathway.

\section{Discussion}

In the present study, we demonstrated that Nrf2 expression in bronchial epithelial cells in COPD subjects was significantly lower than that in control subjects. In addition, we immunohistochemically showed that Nrf2 expression in alveolar epithelial cells was significantly lower than that in control subjects. Nrf2 plays an important role as the master regulator of antioxidant responses [13]. Nrf2 is constitutively expressed in almost
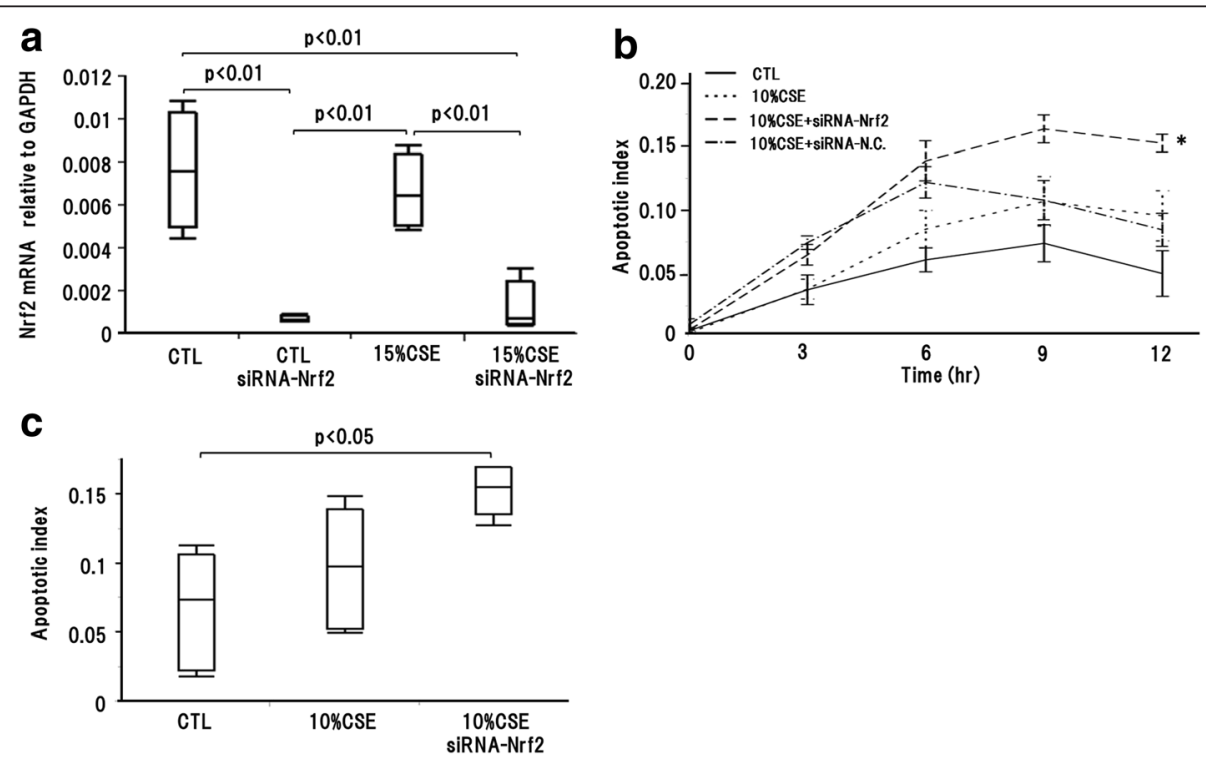

Fig. 6 Effect of Nrf2 knock down on CSE induced apoptosis. a The siRNA-Nrf2 complex transfection with A549 cell significantly decreased Nrf2 mRNA expression in CTL and $15 \%$ CSE. b Apoptotic index was increased over time in $10 \%$ CSE or $10 \%$ CSE with Nrf2 knockdown compared with CTL. *: $p<0.05$ compared with CTL. c Apoptotic index was not significantly increased in $10 \%$ CSE compared with CTL, while significantly increased in $10 \%$ CSE with Nrf2 knockdown compared with CTL. CTL: control 
a

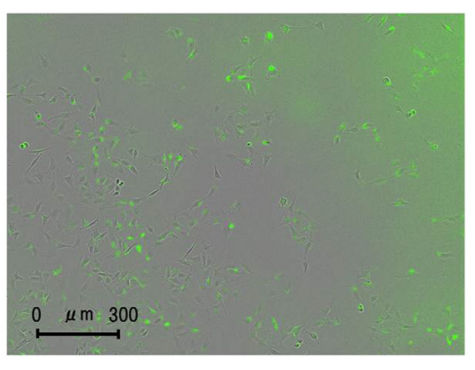

$15 \%$ CSE $12 \mathrm{~h}$

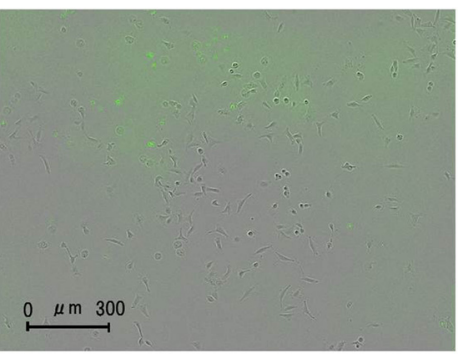

$15 \% \mathrm{CSE}+1.0 \mathrm{mM} \mathrm{NAC} 12 \mathrm{~h}$

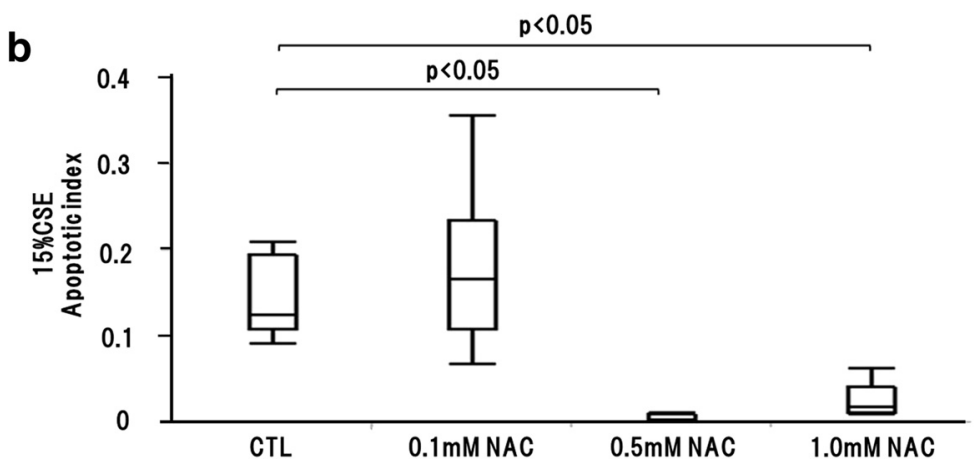

Fig. 7 Effect of NAC pretreatment on CSE induced apoptosis. a Green fluorescent staining by caspase-3/7 reagent revealed apoptosis cells. The number of green fluorescent staining was decreased in $15 \%$ CSE with $1.0 \mathrm{mM} \mathrm{NAC}$ pretreatment. b Pretreatment with 0.1 mM NAC did not decrease $15 \%$ CSE induced apoptotic index, whereas pretreatment with 0.5, 1.0 mM NAC significantly decreased $15 \%$ CSE induced apoptotic index

all cell types and tissues, and is most abundant in tissues where detoxification reactions occur routinely, including the lungs. However, Nrf2 is also inducible and triggered by oxidative stress, injury, and inflammation. Cigarette smoke contains a substantial ROS, and exposure to cigarette smoke is known to induce transient Nrf2 expression in human airway cells. Upon stimulation, cytosolic Nrf2 reaches the nucleus and binds to ARE in the upstream promoter region of antioxidant genes and initiates transcription [4]. Among these, the glutathione cysteine ligase catalytic subunit (GCLC) and glutathione cysteine ligase modifier subunit (GCLM) are important for antioxidant defense. Nrf2 is required for the constitutive and inducible expression of GCLC and GCLM, which are required for glutathione (GSH) synthesis [14]. Impaired Nrf2 expression in COPD patients might fail to evoke an appropriate antioxidant response and allow excessive apoptosis resulting in lung tissue destruction and emphysema. A previous cohort study showed that certain polymorphisms of the Nrf2 gene correlated with accelerated limitations in airflow of smokers $[15,16]$. Subjects with impaired Nrf2 might be related to COPD.

Cigarette smoke causes oxidative stress, enhances inflammation, inactivates critical anti-proteinase inhibitors such as $\alpha 1$-antitrypsin [17], and causes apoptosis of alveolar cells [18]. To determine the appropriate conditions for in vitro CSE study, we used the $\mathrm{pH}$ of $\mathrm{EBC}$ as a reference. Collection of $\mathrm{EBC}$ is a non-invasive and repeatable technique for monitoring the airway milieu. $\mathrm{EBC} \mathrm{pH}$ is known to correlate with oxidative stress and $\mathrm{H}_{2} \mathrm{O}_{2}$ concentration [19]. A previous report observed that the mean $\mathrm{EBC} \mathrm{pH}$ in patients with COPD and nonCOPD smokers was significantly lower than that in non-smoking subjects [20]. We measured EBC pH before and after smoking and found that the EBC $\mathrm{pH}$ was immediately lowered after smoking. Our results confirmed that cigarette smoking caused oxidative stress in the human airway. We chose $10 \%$ and $15 \%$ CSE as treatments and $100 \mu \mathrm{M} \mathrm{H}_{2} \mathrm{O}_{2}$ as a positive control in in vitro CSE experiments. We determined the effect of oxidative stress by CSE on apoptosis over time using IncuCyte ZOOM and showed that the apoptotic index increased significantly at $12 \mathrm{~h}$ after treatment with $10 \%$ and $15 \%$ CSE. Because the doubling time of A549 cell is about $22 \mathrm{~h}$ and in order to avoid influence of cell division and growth, we adopted a 12-h time point for evaluation. Although we used caspase-3/7 activation as an indicator of apoptosis, we performed TUNEL staining to confirm apoptosis. The apoptosis index of A549 cells increased in a CSE dose-dependent manner. This is consistent with other in vitro studies in BEAS-2B cells [21]. However, alveolar epithelial cells are robustly involved in the pathogenesis of emphysema through the alveolar wall destruction and/or the loss due to 
epithelial cells apoptosis [22]. Thus, in this study we used A549 cells, alveolar epithelial cell line, instead of BEAS-2B cells.

Nrf2 is thought to be a key determinant of COPD susceptibly [23-26]. We examined the effect of Nrf2 knockdown on CSE-induced apoptosis. Nrf2 knockdown significantly increased $10 \%$ CSE-induced apoptosis. In previous animal studies, Nrf2-/- mice were reported to be highly susceptible to cigarette smoke-induced lung injury $[5,6]$. On the other hand, Nrf2 overexpression protected from cell apoptosis by cigarette smoke exposure $[27,28]$. The present results support the idea that impaired Nrf2 expression plays an important role in apoptosis. We also explored the mechanism behind CSE-induced apoptosis. Caspase activation commits cells to one of two distinct but convergent pathways: the death receptor pathway and the mitochondrial pathway. The death receptor pathway is activated when members of the TNF- $\alpha$ superfamily bind to cell surface "death receptor" members of the TNF- $\alpha$ receptor family. Initiators of the mitochondrial pathway increase intracellular ROS, DNA damage, the unfolded protein response, and the deprivation of growth factor [29]. In the present study, we showed that NAC ameliorates CSE-induced apoptosis. However, antiTNF- $\alpha$ antibody could not ameliorate CSE-induced apoptosis. CSE-induced apoptosis of A549 cells was dependent on the mitochondrial pathway following oxidative stress and independent of the death receptor pathway in this in vitro setting. NAC is a precursor of GSH, which is one of the most important antioxidants for protecting cells and tissue from ROS. GSH and NAC act as oxygen free radical scavengers [30]. GCLC, GCLM, and glutathione reductase (GR) are also critical for GSH. Our results showed that oxidative stress induced by CSE played a key role in apoptosis. Imbalance between oxidants and antioxidants is thought to be involved in the development of pulmonary emphysema [31, 32]. Thus, oxidative stress is an important therapeutic target, and NAC is thought to be a potential drug for COPD [3336]. Although the BRONCUS study showed that NAC is ineffective at preventing COPD exacerbation in patients [37], other reports have shown that high-dose NAC significantly reduced COPD exacerbations [38, 39]. Therapies targeting oxidative stress are gradually showing more promising outcomes. The limitations of this study are: (1) small number of participants and (2) cell source (we collected epithelial cells around the sixth branch, not the alveolar region, for technical reasons). However, the present study is an important and extensive investigation into the relationship between $\mathrm{Nrf} 2$ and oxidative stress in airway compartments of patients with COPD.

\section{Conclusions}

We demonstrated that Nrf2 expression in patients with COPD was lower than that in control subjects, suggesting that impaired Nrf2 expression might be related to
COPD. Further research into the molecular mechanisms involved in Nrf2 expression in COPD airways and therapies to upregulate Nrf2 are needed. Administration of antioxidants to patients with COPD may be a basic therapeutic option to consider in addition to the current bronchodilator therapy.

\section{Abbreviations}

ARE: Antioxidant response element; COPD: Chronic obstructive pulmonary disease; CSE: Cigarette smoke extracts; GCLC: Glutathione cysteine ligase catalytic subunit; GCLM: Glutathione cysteine ligase modifier subunit; NAC: N-acetyl cysteine; Nrf2: Nuclear factor erythroid 2-related factor 2; ROS: Reactive oxygen species.

\section{Competing interests}

The authors declare that they have no competing interests.

\section{Authors' contributions}

KY performed the data collection, data and statistical analysis, interpretation of the results, and article drafting. KA designed this study, contributed data analysis and performed article drafting. FN, $\mathrm{KS}, \mathrm{NI}, \mathrm{NY}$ and $\mathrm{Yl}$ performed the sample collection. TW, YT, HK and KH performed interpretation of the results and revised the manuscripts. All authors have read and approved the final manuscript

\section{Acknowledgements}

This work was supported by Grant-in-Aid for Scientific Research (C) from Japan Society for the Promotion of Science (JSPS) 15 K09185.

Received: 28 August 2015 Accepted: 28 January 2016

Published online: 09 February 2016

\section{References}

1. Hogg JC, Timens W. The pathology of chronic obstructive pulmonary disease. Annu Rev Pathol. 2009:4:435-59.

2. Church DF, Pryor WA. Free-radical chemistry of cigarette smoke and its toxicological implications. Environ Health Perspect. 1985;64:111-26.

3. Sinha K, Das J, Pal PB, Sil PC. Oxidative stress: the mitochondria-dependent and mitochondria-independent pathways of apoptosis. Arch Toxicol. 2013; 87(7):1157-80

4. Kensler TW, Wakabayashi N, Biswal S. Cell survival responses to environmental stresses via the Keap1-Nrf2-ARE pathway. Annu Rev Pharmacol Toxicol. 2007;47:89-116.

5. lizuka T, Ishii Y, Itoh K, Kiwamoto T, Kimura T, Matsuno Y, et al. Nrf2-deficient mice are highly susceptible to cigarette smoke-induced emphysema. Genes Cells. 2005:10(12):1113-25.

6. Rangasamy T, Cho CY, Thimmulappa RK, Zhen L, Srisuma SS, Kensler TW, et al. Genetic ablation of Nrf2 enhances susceptibility to cigarette smokeinduced emphysema in mice. J Clin Invest. 2004;114(9):1248-59.

7. Yageta Y, Ishii Y, Morishima Y, Ano S, Ohtsuka S, Matsuyama M, et al. Carbocisteine reduces virus-induced pulmonary inflammation in mice exposed to cigarette smoke. Am J Respir Cell Mol Biol. 2014;50(5):963-73.

8. Cho HY, Jedlicka AE, Reddy SP, Kensler TW, Yamamoto M, Zhang LY, et al. Role of NRF2 in protection against hyperoxic lung injury in mice. Am J Respir Cell Mol Biol. 2002;26(2):175-82.

9. Global strategy for the diagnosis, management, and prevention of chronic obstructive pulmonary disease. http://www.goldcopd.org/quidelines-globalstrategy-for-diagnosis-management.html (2015)

10. Asano H, Horinouchi T, Mai Y, Sawada O, Fujji S, Nishiya T, et al. Nicotineand tar-free cigarette smoke induces cell damage through reactive oxygen species newly generated by PKC-dependent activation of NADPH oxidase. J Pharmacol Sci. 2012;118(2):275-87.

11. Murata K, Fujimoto K, Kitaguchi Y, Horiuchi T, Kubo K, Honda T. Hydrogen peroxide content and $\mathrm{pH}$ of expired breath condensate from patients with asthma and COPD. COPD. 2014;11(1):81-7

12. Berghauser Pont LM, Kleijn A, Kloezeman JJ, van den Bossche W, Kaufmann JK, de Vrij J, et al. The HDAC Inhibitors Scriptaid and LBH589 Combined with the Oncolytic Virus Delta24-RGD Exert Enhanced Anti-Tumor Efficacy in Patient-Derived Glioblastoma Cells. PLoS One. 2015;10(5):e0127058. 
13. Bocci V, Valacchi G. Nrf2 activation as target to implement therapeutic treatments. Front Chem. 2015;3:4.

14. Harvey CJ, Thimmulappa RK, Singh A, Blake DJ, Ling G, Wakabayashi N, et al. Nrf2-regulated glutathione recycling independent of biosynthesis is critical for cell survival during oxidative stress. Free Radic Biol Med. 2009;46(4):443-53.

15. Sasaki H, Suzuki A, Shitara M, Hikosaka Y, Okuda K, Moriyama S, et al. Polymorphisms of NRF2 gene correlated with decreased FEV1 in lung cancers of smokers. Biomed Rep. 2013;1(3):484-8.

16. Masuko H, Sakamoto T, Kaneko Y, lijima H, Naito T, Noguchi E, et al. An interaction between Nrf2 polymorphisms and smoking status affects annual decline in FEV1: a longitudinal retrospective cohort study. BMC Med Genet. 2011;12:97.

17. MacNee W, Rahman I. Is oxidative stress central to the pathogenesis of chronic obstructive pulmonary disease? Trends Mol Med. 2001;7(2):55-62.

18. Tuder RM, Zhen L, Cho CY, Taraseviciene-Stewart L, Kasahara Y, Salvemini D, et al. Oxidative stress and apoptosis interact and cause emphysema due to vascular endothelial growth factor receptor blockade. Am J Respir Cell Mol Biol. 2003;29(1):88-97.

19. Kostikas K, Papatheodorou G, Ganas K, Psathakis K, Panagou P, Loukides S. $\mathrm{pH}$ in expired breath condensate of patients with inflammatory airway diseases. Am J Respir Crit Care Med. 2002;165(10):1364-70.

20. MacNee W, Rennard SI, Hunt JF, Edwards LD, Miller BE, Locantore NW, et al. Evaluation of exhaled breath condensate $\mathrm{pH}$ as a biomarker for COPD. Respir Med. 2011;105(7):1037-45.

21. Lin XX, Yang XF, Jiang JX, Zhang SJ, Guan Y, Liu YN, et al. Cigarette smoke extract-induced BEAS-2B cell apoptosis and anti-oxidative Nrf-2 upregulation are mediated by ROS-stimulated p38 activation. Toxicol Mech Methods. 2014;24(8):575-83.

22. Aoshiba K, Yokohori N, Nagai A. Alveolar wall apoptosis causes lung destruction and emphysematous changes. Am J Respir Cell Mol Biol. 2003; 28(5):555-62.

23. Sussan TE, Rangasamy T, Blake DJ, Malhotra D, El-Haddad H, Bedja D, et al. Targeting Nrf2 with the triterpenoid CDDO-imidazolide attenuates cigarette smoke-induced emphysema and cardiac dysfunction in mice. Proc Natl Acad Sci U S A. 2009;106(1):250-5.

24. Boutten A, Goven D, Boczkowski J, Bonay M. Oxidative stress targets in pulmonary emphysema: focus on the Nrf2 pathway. Expert Opin Ther Targets. 2010;14(3):329-46.

25. Goven D, Boutten A, Leçon-Malas V, Marchal-Sommé J, Amara N, Crestani B, et al. Altered Nrf2/Keap1-Bach1 equilibrium in pulmonary emphysema. Thorax. 2008;63(10):916-24.

26. Malhotra D, Thimmulappa R, Navas-Acien A, Sandford A, Elliott M, Singh A, et al. Expression of concern: Decline in NRF2-regulated antioxidants in chronic obstructive pulmonary disease lungs due to loss of its positive regulator, DJ-1. Am J Respir Crit Care Med. 2008;178(6):592-604.

27. Kosmider B, Messier EM, Chu HW, Mason RJ. Human alveolar epithelial cell injury induced by cigarette smoke. PLoS One. 2011;6(12):e26059.

28. Huang C, Wang JJ, Ma JH, Jin C, Yu Q, Zhang SX. Activation of the UPR protects against cigarette smoke-induced RPE apoptosis through upregulation of Nrf2. J Biol Chem. 2015;290(9):5367-80.

29. Hotchkiss RS, Strasser A, MCDunn JE, Swanson PE. Cell death. N Engl J Med. 2009;361(16):1570-83.

30. Nagata K, Iwasaki Y, Yamada T, Yuba T, Kono K, Hosogi S, et al. Overexpression of manganese superoxide dismutase by $\mathrm{N}$-acetylcysteine in hyperoxic lung injury. Respir Med. 2007;101(4):800-7.

31. Carp H, Janoff A. Possible mechanisms of emphysema in smokers. In vitro suppression of serum elastase-inhibitory capacity by fresh cigarette smoke and its prevention by antioxidants. Am Rev Respir Dis. 1978;118(3): 617-21.

32. Snider GL. Emphysema: the first two centuries-and beyond. A historical overview, with suggestions for future research: Part 1. Am Rev Respir Dis. 1992;146(5 Pt 1):1334-44

33. Cai S, Chen P, Zhang C, Chen JB, Wu J. Oral N-acetylcysteine attenuates pulmonary emphysema and alveolar septal cell apoptosis in smokinginduced COPD in rats. Respirology. 2009;14(3):354-9.

34. Dekhuijzen PN, van Beurden WJ. The role for N-acetylcysteine in the management of COPD. Int J Chron Obstruct Pulmon Dis. 2006;1(2):99-106.

35. Sadowska AM, Luyten C, Vints AM, Verbraecken J, Van Ranst D, De Backer WA. Systemic antioxidant defences during acute exacerbation of chronic obstructive pulmonary disease. Respirology. 2006;11(6):741-7.
36. Decramer M, Rutten-van Mölken M, Dekhuijzen PN, Troosters T, van Herwaarden C, Pellegrino R, et al. Effects of N-acetylcysteine on outcomes in chronic obstructive pulmonary disease (Bronchitis Randomized on NAC Cost-Utility Study, BRONCUS): a randomised placebo-controlled trial. Lancet. 2005;365(9470):1552-60.

37. Tse HN, Raiteri L, Wong KY, Yee KS, Ng LY, Wai KY, et al. High-dose $\mathrm{N}$-acetylcysteine in stable COPD: the 1-year, double-blind, randomized, placebo-controlled HIACE study. Chest. 2013;144(1):106-18.

38. Zuin R, Palamidese A, Negrin R, Catozzo L, Scarda A, Balbinot M. High-dose $\mathrm{N}$-acetylcysteine in patients with exacerbations of chronic obstructive pulmonary disease. Clin Drug Investig. 2005;25(6):401-8.

39. Tse HN, Raiteri L, Wong KY, Ng LY, Yee KS, Tseng CZ. Benefits of high-dose $\mathrm{N}$-acetylcysteine to exacerbation-prone patients with COPD. Chest. 2014; 146(3):611-23.

\section{Submit your next manuscript to BioMed Central and we will help you at every step:}

- We accept pre-submission inquiries

- Our selector tool helps you to find the most relevant journal

- We provide round the clock customer support

- Convenient online submission

- Thorough peer review

- Inclusion in PubMed and all major indexing services

- Maximum visibility for your research

Submit your manuscript at www.biomedcentral.com/submit
Biomed Central 